\title{
DA ESCOLA NO QUILOMBO À ESCOLA DO QUILOMBO: a prática pedagógica como elemento substancial para fortalecer sentidos de pertencimentos identitários
}

\author{
JERÔNIMO JORGE CAVALCANTE SILVA
}

Doutor em Educação pela Universidade Autônoma de Barcelona-Espanha. Pós-Doutor em Educação pela Universidade de Cádiz-Espanha. Professor Titular no Mestrado Profissional em Educação e Diversidade, da Universidade do Estado da Bahia - MPED UNEB. Membro do Grupo de Pesquisa Diversidade, Formação, Educação Básica e Discursos - DIFEBA. Email: jorgeazu153@gmail.com

\section{DANIELMA DA SILVA BEZERRA BRASILEIRO}

Professora da Rede Municipal de Ensino de Caldeirão Grande/BA. Pedagoga. Mestranda do Programa de Pós-Graduação em Educação e Diversidade da Universidade do Estado da Bahia - MPED UNEB - Departamento de Ciências Humanas - Campus IV. Integrante do Grupo de Pesquisa - Diversidade, Formação, Educação Básica e Discursos DIFEBA.

Email: dani.bbbahia@hotmail.com 
O trabalho dessa pesquisa - Da escola no quilombo à escola do quilombo: a prática pedagógica como elemento substancial para fortalecer sentidos de pertencimentos identitários - se propõe a discutir sobre as Práticas Pedagógicas docentes da Educação Escolar Quilombola e como essas práticas fazem interface com a realidade sociocultural dos alunos do Ensino Fundamental II da Escola Municipal Quintina Marculina dos Santos, na Comunidade Quilombola de Raposa, zona rural do município de Caldeirão Grande/Bahia.

A educação sempre foi considerada o caminho mais eficaz para a solução dos problemas ligados a aquisição de direitos, liberdade e igualdade entre os homens. Temos uma Constituição Federal, Diretrizes e Estatuto da Igualdade Racial, entre outras normativas; mas é comum vermos um país que se diz democrático e multirracial insistir na contramão entre diversidade e ensino.

Pesquisas denunciam que os fatores que compõem o ambiente escolar desfavorecem o aluno quilombola; pois, o ensino hegemônico/eurocêntrico mantém a história e a cultura quilombola no anonimato e não consolidam um planejamento com práticas pedagógicas que visem o fortalecimento e a valorização da história e cultura afro-brasileira.

Considerando esse contexto, questionamos: como são construídas as Práticas Pedagógicas na Educação Escolar Quilombola pelos docentes do Ensino Fundamental II da Escola Municipal Quintina Marculina dos Santos? De que forma eles fazem interface com a realidade sociocultural dos alunos?

Procuramos ampliar os estudos sobre a Educação Escolar Quilombola refletindo sobre os processos sócio-históricos, políticos, culturais e suas legislações - Brasil (1988; 1998; 2002; 2003; 2005; 2010; 2012); em Fiabani (2008), Leite (2008), Gomes (2008), Conceição (2016), Miranda (2001; 2009; 2012); além de bucar conhecer como são construídas as práticas pedagógicas dentro da escola em Libâneo (1994), Perrenoud (1993; 2001), Pimenta (2002), Veiga (1991; 1994), Sacristán; Goméz (1998); Zabala (2014) e Estrela (1994); e se estão favorecendo o fortalecimento ou a inibição da/s identidade/s dos alunos - Hall (2003 e 2006), Munanga (1996; 1999; 2012), Silva (2005), Woodward (2011), Brauman (2005) Miranda (2009; 2012).

A pesquisa ancora-se em uma abordagem qualitativa dentro da fenomenologia e se constitui através de um Estudo de Caso Etnográfico o qual, segundo Gil (2010), caracteriza-se por ser um estudo minucioso pela observação participante ao explicar padrões causais ou estruturais, procurando obter uma maior percepção da realidade estudada no seu ambiente natural, na coleta de informações diretas da fonte, examinando fatos, comportamentos, documentos, as narrativas de

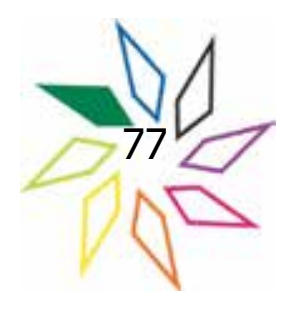


todo corpo docente possibilitando aproximação das questões pesquisadas para poder caracterizar o espaço escolhido, o contexto e a realidade.

Temos como público-alvo 05 professores da Educação Básica, 01 coordenador pedagógico e um diretor escolar. Como critérios de inclusão/exclusão para a nossa pesquisa, utilizamos: ser professor efetivo da escola Municipal Quintina Marculina dos Santos; lecionar no $6^{\circ}, 7^{\circ}$ e $8^{\circ}$ ano do Ensino Fundamental II; ser membro da coordenação pedagógica e estar inserido na gestão administrativa da escola. Como instrumento de construção de dados, elegemos: questionários - pela dinâmica de aplicação que dispensa a presença do pesquisador e por possibilitar o uso eficiente do tempo; entrevistas - por ser uma técnica importante para obter as informações e atender aos objetivos da pesquisa; observação participante - indispensável à análise das práticas pedagógicas levando em consideração a temática em estudo e o grupo focal por nos possibilitar que os sujeitos possam expor e reorganizar as suas opiniões, visões e experiências no que tange a temática debatida (GATTI, 2012).

Como plano de intervenção, objetivamos a construção coletiva de um Documento Paradidático - "Olhares dos Professores sobre a Educação Escolar Quilombola na Educação Básica" -, com o objetivo de produzir um Plano de Ação que atenda e valorize as especificidades da cultura local sob a perspectiva das práticas pedagógicas e suas implicações nas relações étnico-raciais.

Para a análise de dados tomaremos como base o conjunto de técnicas de análise das comunicações e procedimentos sistemáticos que busca a descrição do conteúdo e das suas mensagens composto pela Análise do conteúdo (BARDIN, 2006).

O interesse em apresentar esta proposta de pesquisa surgiu a partir da reflexão e desdobramento de outras pesquisas desenvolvidas na Comunidade Quilombola de Raposa em Caldeirão Grande/BA ${ }^{1}$. Pesquisas pioneiras, realizadas no Quilombo de Raposa - intituladas Perspectivas da inclusão da questão racial no currículo escolar e O Quilombo de Raposa e seus sujeitos de direitos - possibilitaram uma discussão ampliada sobre a Lei 10 639/03 e a formação

1 Localizada na região Piemonte Norte do Itapicuru - $333 \mathrm{~km}$ da capital baiana - com 12.485 habitantes, "recebeu este nome devido aos grandes caldeirões de pedra, conhecidos como "LAGE" onde se juntam as águas das chuvas e por isso, passou a chamar-se: Caldeirão Grande. Fonte: Histórico do município, 2015. 
dos professores, assim como a mobilizando da comunidade para a construção da Associação Quilombola de Raposa², além de ter motivado a Certificação pela Fundação Cultural Palmares.

Diante de destas conquistas sociais e das tentativas em aproximar a escola com seus agentes na construção de diálogos condizentes com o respeito à diversidade e a cultura local palestras, rodas de conversas, projetos pedagógicos -, a escola ainda não conseguiu avançar no mesmo ritmo que a comunidade. Percebemos que a escola não tem valorizado a herança cultural do seu povo e não se apropria da sua legitimidade; ressalta a história e culturas de outros lugares esquecendo-se do seu histórico; não tem um Projeto Político Pedagógico atualizado como uma "escola quilombola"; não incentiva seus alunos com práticas pedagógicas que fortaleçam suas identidades étnicas.

Por isso, nasceu o desejo de discutir sobre as Práticas Pedagógicas e suas concepções na educação escolar quilombola - em consonância com as Diretrizes Curriculares Nacionais para a Educação das Relações Étnico-Raciais e para o Ensino de História e Cultura Afro-brasileira e Africana analisando de que forma os docentes fazem interface com a realidade sociocultural desses sujeitos. Desta forma é necessário um estudo mais amplo e aprofundado para que assim possamos "descortinar" esta realidade tão presente e desenvolver um trabalho que mobilize todos os envolvidos ratificando a importância de promover práticas pedagógicas que ressignifiquem o universo cultural dos alunos quilombolas para dentro dos portões da escola, mesmo diante dos desafios encontrados e das forças de resistência que ainda permanecem atreladas a uma visão retrógrada de um ensino mecânico e tecnicista.

\section{REFERÊNCIAS}

BARDIN, L. Análise de conteúdo. Lisboa, 2006.

BRASIL. Constituição da República Federativa do Brasil. Ato das Disposições Constitucionais Transitórias-ADCT. Brasília: Senado, 1988.

\section{. Diretrizes Curriculares Nacionais para a Educação das Relações Étnico-Raciais e}

\footnotetext{
2 Grupo organizado que tem lutado pela efetivação de seus direitos - os anseios pela Regulamentação Fundiária da Terra; a conquista de vários Projetos Sociais como o PRONATEC e o Curso Mulheres Mil através do IFBA; o Programa Nossa Sopa e o Projeto Água Saudável através das Voluntárias Sociais da Bahia; a Inclusão das famílias quilombolas no cadastro do Programa Bolsa Família e no Programa Cestas Básicas Quilombolas.
} 
para o Ensino de História e Cultura Afro-brasileira e Africana. Brasília: junho, 2005.

Diretrizes Curriculares Nacionais para a Educação Escolar Quilombola. Reso-

lução No 8, de 20 de Novembro de 2012. Brasília: Conselho Nacional de Educação - Câmara de Educação Básica (CNE/CEB).

CONCEIÇÃO, Joanice Santos. QUANDO O ASSUNTO É SOBRE RELIGIÕES DE MATRIZ AFRICANA: LEI 10.639/2003. In: Revista da FAEEBA - Educação e Contemporaneidade, Salvador, v. 25, n. 45, p. 113-126, jan./abr. 2016. http://www.revistas.uneb.br/index.php/ faeeba/issue/current Acesso em 05.05. 2016.

ESTRELA, Maria Teresa. Relação Pedagógica, disciplina e indisciplina na aula. Portugal: Porto, 1994.

FIABANI, Adelmir. Os novos quilombos: a luta pela terra e afirmação étnica no Brasil. [1988-2008]. São Leopoldo: Programa de Pós-Graduação em História/UNISINOS, 2008.

FREIRE, Paulo. Pedagogia da Autonomia: saberes necessários à prática educativa. São Paulo, SP: Paz e Terra, 1996.

GATTI, Bernadete Angelina. Grupo Focal na Pesquisa em ciências sociais e humanas. Brasília: Liber Livro, 2012.

GIL, Antonio Carlos. Como elaborar Projetos de Pesquisa. São Paulo: Atlas, 2010.

GOMES, Nilma Lino. Diversidade Étnico-racial e a Educação Brasileira. In: Diversidade Cultural da proteção à promoção. Belo Horizonte/MG: Autêntica, 2008.

HALL, Stuart. A identidade Cultural na pós-modernidade. Rio de janeiro, RJ: DP\&A, 2011.

LEITE, Ilka Boaventura. O Projeto Político Quilombola: desafios, conquistas e impasses atuais. In: Estudos Feministas. Vol. 16, p. 965-977. No. 3 - setembro-dezembro - 2008.

MIRANDA, Carmélia A. S. Identidade, Reconhecimento e Auto-Estima: as experiências dos remanescentes do quilombo de Tijuaçu-BA. In: GARCIA, Paulo César Souza. (Org.). Interfaces: cultura, contemporaneidade e subjtividades. Salvador: EDUNEB, 2009

MUNANGA, Kabengele. Rediscutindo a mestiçagem no Brasil: Identidade nacional versus identidade negra. Petrópolis, RJ: Vozes, 1999.

PERRENOUD, Philippe. Ensinar: agir na urgência, decidir na incerteza: saberes e compe- 
tências em uma profissão complexa. Porto Alegre: Artemed, 2001.

PIMENTA, Selma Garrido. Saberes pedagógicos e atividade docente. São Paulo: Cortez, 2002.

SACRISTÁN, J. Gimeno; GOMÉZ, A. I. Pérez. Compreender e transformar o ensino. São Paulo: Artmed, 1998.

SANTOS, Boaventura de Souza. Pela mão de Alice: o social e o político na pós-modernidade. São Paulo: Cortez, 2006.

SILVA, A. C. A desconstrução da discriminação no livro didático. In. MUNANGA, K. (Org.). Superando o racismo na escola. Brasília, DF: Ministério da Educação/Secretaria de Educação Continuada, Alfabetização e Diversidade, 2005.

VEIGA, Ilma Passos Alencastro. Técnicas de ensino: por que não? Campinas, SP: Papirus, 1991.

WOODWARD, Kathryn. Identidade e diferença na perspectiva dos Estudos Culturais. In: Identidade e diferença: uma introdução teórica e conceitual. Petrópolis, RJ: Vozes, 2011.

ZABALA, Antoni. A prática educativa: como ensinar. Porto Alegre: Penso, 2014. 